\title{
Natural minerals impact on physical and chemical parameters of potable water
}

\author{
Anton Martsev ${ }^{1, *}$ and Oleg Selivanov ${ }^{1}$ \\ ${ }^{1}$ Vladimir State University named after A.G. and N.G. Stoletovs', Gorky Street 87, 600000, Vladimir, \\ Russia
}

\begin{abstract}
The article presents the research results dealing with the influence of such natural minerals as flint and shungite in relation to the following water parameters $\mathrm{pH}$, TDS, conductivity, cations $(\mathrm{NH} 4+, \mathrm{K}+$, $\mathrm{Na}+, \mathrm{Mg} 2+, \mathrm{Sr} 2+, \mathrm{Ba} 2+, \mathrm{Ca} 2+)$ and anions $(\mathrm{Cl}-, \mathrm{SO} 42-, \mathrm{NO} 3-, \mathrm{F}-$, $\mathrm{CO} 32-)$. It was found that crushed flint and shungite added to the water more significantly increases water hydrogen index if compared to sedimentation. Simultaneously total water mineralization decreases (causing electric 28,4 al conductivity decrease). Considerable decrease in calcium ions concentration (by $36.0 \%$ ) was detected in the water infused with shungite and by $20.5 \%$ in the water infused with flint. Considerable increase in $\mathrm{K}+$ ions concentration in water infused with flint (46.3\%) was revealed. As for the anions $\mathrm{F}-$ concentration decreased for both minerals - shungite and flint. These natural minerals are recommended for the treatment of tap water characterized with the increased hardness and excessive fluoride ions content.
\end{abstract}

\section{Introduction}

Nowadays the water quantity used by people for drinking and technical purposes is increasing annually. Herewith the water used from natural surface sources is so heavily polluted that it is harmful to use it for drinking and technical purposes without preliminary treatment. It might contain high concentrations of heavy metals, petroleum products, phenols, complex organochlorines, antibiotics, surfactants, pesticides, free radicals, pathogenic microorganisms, etc. To purify heavily polluted water to reach the regulatory requirements, modern complex multi-stage water treatment technologies based on ultra- and nanofiltration, reverse osmosis, ion exchange, evaporation, electrochemical treatment methods, ultraviolet radiation, etc. are applied [1-4]. These water treatment technologies are complex and very expensive. Water used for drinking purposes from underground artesian wells in each region has its own specific physical and chemical characteristics, specified by the natural factors of a particular geographical area. Increased total hardness and increased fluorine and manganese ions in some parts of the region are such features of physical and chemical composition of natural underground water used for drinking purposes in Central Russia and, in particular, in the Vladimir region, the [5-8].

\footnotetext{
* Corresponding author: martsevaa@yandex.ru
} 
Currently, the problem water treatment for drinking purposes is quite relevant. For this purpose at home the population is widely applying not only house filters, but also inexpensive natural minerals (shungite, mudstone, mountain quartz, flint, etc.) used for extracting on filtered water. Such natural minerals as shungite and flint are of great interest for water purification, as they are widely spread, inexpensive and possess unique sorption properties. Nowadays shungite and flint application have been studied not only for water purification [912], but also in agriculture [13], microbiology and technological production [14-15].

Thus, comprehensive study of these natural minerals properties is very urgent. Our research objective is to study the influence of natural minerals shungite and flint on physical and chemical parameters of drinking water.

\section{Materials and methods}

Flint and shungite were selected as natural minerals to assess their impact on the physical and chemical parameters of water. Crushed mineral rock of 4-8 mm average fraction size was prepared for the experiments. The natural mineral shungite from Zazhoginsky deposit located in Karelia and mineral flint from Dobryatinsky deposit of the Vladimir region were used. The shungite composition from Zazhoginsky deposit beside carbon, includes the following compounds (wt.\%): $\mathrm{SiO}_{2}-57.0 ; \mathrm{Al}_{2} \mathrm{O}_{3}-4.1 ; \mathrm{TiO}_{2}-0.2$; FeO-0.6; MnO-0.16; S -1.2; $\mathrm{K}_{2} \mathrm{O}-1.5$. The flint composition in addition to $\mathrm{SiO}_{2}$ (94 wt.\%) contains various oxides (wt.\%): $\mathrm{Al}_{2} \mathrm{O}_{3}$ (0.4-1), $\mathrm{Fe}_{2} \mathrm{O}_{3}(0.2-0.6), \mathrm{CaO}(0.2-1.0)$, as well as b (mcg/g): $\mathrm{Ba}(50-60)$, Ti (36-120), $\mathrm{Mn}$ $(10-50), \mathrm{B}(25-100), \mathrm{Ni}, \mathrm{Cu}, \mathrm{Y}(3-10)$.

The experimental method was as follows: 3 glass flasks were filled with $500 \mathrm{~cm} 3$ of tap water, than $15 \mathrm{~g}$ of crushed flint and shungite were placed in 2 flasks. The 3rd flask (control) contained only water. The static experiments lasted 11 days. The samples from the flasks for the analysis of water physical and chemical parameters after extraction on crushed flint and shungite were taken on the 1st, 4th, 7th and 11th days. Samples from the control flask were taken at the same time interval. The experiments were repeated twice. The water hydrogen index was determined using $\mathrm{pH}$ meter HI 83141 "HANNA". Total mineralization and electrical conductivity were determined using conductometer and salt meter HI 9835 "HANNA". The quantitative amount of cations (NH4+, $\mathrm{K}+, \mathrm{Na}+, \mathrm{Mg} 2+, \mathrm{Sr} 2+, \mathrm{Ba} 2+, \mathrm{Ca} 2+$ ) and anions $(\mathrm{Cl}-, \mathrm{SO} 42-, \mathrm{NO} 3-, \mathrm{F}-, \mathrm{CO} 32-)$ in the water samples was determined using capillary electrophoresis system "Kapel-104T" according to PND F 14.1:2:4.167-2000 methods (for cations determination) and PND F 14.1:2:4.157-99 (for anions determination).

Statistics was processed using Statistica software. The statistically significant difference between experience and control was determined using the t-test for two independent samples in Statistica.

\section{Results and discussion}

The experiments revealed that during 11 days the hydrogen index rise was detected for both tap water infused with shungite and flint, and in the control sample. Table 1 shows the physical and chemical parameters of tap water infused with shungite and flint, the samples were taken on the $1 \mathrm{st}, 4$ th, 7 th, and 11 th day.

Table 1. Physical and chemical parameters of tap water enfused with shungite and flint 


\begin{tabular}{|c|c|c|c|c|c|}
\hline \multicolumn{7}{|c|}{ Hydrogen index (pH), un. } \\
\hline & 0 day & 1 day & 4 day & 7 day & 11 day \\
\hline Control & 7.72 & 8.01 & 8.32 & 8.40 & 8.39 \\
\hline Shungite & 7.72 & 8.30 & 8.52 & 8.51 & 8.55 \\
\hline Flint & 7.72 & 8.29 & 8.51 & 8.52 & 8.54 \\
\hline \multicolumn{7}{|c|}{ Total mineralization, mg/l } \\
\hline Control & 197.0 & 197.1 & 196.3 & 197.3 & 18 day \\
\hline Shungite & 197.0 & 189.5 & 173.2 & 160.5 & 151.1 \\
\hline Flint & 197.0 & 192.5 & 185.5 & 180.1 & 165.5 \\
\hline \multicolumn{7}{|c|}{} & Electric conductivity, $\mu \mathrm{s}$ & 11 day \\
\hline Control & 393.5 & 393.3 & 392.5 & 393.1 & 378.7 \\
\hline Shungite & 393.5 & 378.5 & 350.5 & 321.5 & 302.5 \\
\hline Flint & 393.5 & 384.5 & 371.2 & 359.5 & 330.5 \\
\hline
\end{tabular}

Even on the first day statistically significant $(p=0.000308)$ difference in the hydrogen index $\mathrm{pH}$ from the same indicator at the beginning of the experiment in the control was detected. Statistically significant differences between the experiment and the control are revealed on day $1(\mathrm{p}=0.000459)$. Thus, alkalinization process is significantly more intense in the experimental samples.

In 11 days $\mathrm{pH}$ increased in the control by 0.67 units, and in tap water infused with shungite and flint by 0.83 and 0.84 units, respectively. Thus, in comparison with the control, the influence of natural minerals shungite and flint on the water hydrogen index is obvious.

The process of water settling in the control has not significantly affected the total salinity index (between the control at the beginning of the experiment and on day $11, p=0.056544$ ).

In the experimental samples of tap water, infused with flint, the total mineralization index on day 11 decreased by $16.0 \%(p=0.032827)$, and statistically significant difference became evident on day $4(\mathrm{p}=0.044153)$. In the experimental samples of tap water, infused with shungite, the total mineralization index on day 11 decreased by $23.1 \%$.

Similar results were registered during electrical conductivity analyzing of water samples, infused with flint and shungite, which is quite understandable, since these two indicators are closely related. The total mineralization index decrease in water samples infused with shungite and flint caused the decrease in their electrical conductivity.

Experiments have demonstrated that greater decrease in the total mineralization index was found for the tap water infused with the crushed mineral rock of shungite. It largely depends on shungite high sorption, catalytic and reducing properties of the mineral, which effectiveness is directly related to the nanostructure and composition of the forming elements of shungite carbon. The basis of shungite carbon consists of hollow, multilayer fullerene-like spherical globules, with 10-30 nm diameter, containing packages of carbon layers covering nanopores. Fullerene-like globules might contain from several tens to several hundred of carbon atoms and vary in shape and size. The reticular-spherical structure means that natural carbon fullerenes are ideal sorbents, which is primarily dependable on the presence of a large number of double conjugated bonds and reaction centers on a closed carbon sphere. 
The capillary electrophoresis system "Kapel-104T" assisted in analyzing the cationicanionic composition of water samples infused in the control (C), on shungite (Sh) and flint (F). The results are presented in Tables 2 and 3.

Table 2. Cations amount in control water sample and infused on shungite and flint, (mg/l)

\begin{tabular}{|c|c|c|c|c|c|c|c|c|c|c|c|c|c|}
\hline & 0 & \multicolumn{3}{|c|}{1 day } & \multicolumn{3}{|c|}{4 day } & \multicolumn{3}{|c|}{7 day } & \multicolumn{3}{|c|}{11 day } \\
\hline & & $\mathrm{C}$ & Sh & $\mathrm{F}$ & $\mathrm{C}$ & Sh & $\mathrm{F}$ & $\mathrm{C}$ & Sh & $\mathrm{F}$ & $\mathrm{C}$ & $\mathrm{Sh}$ & $F$ \\
\hline $\begin{array}{c}\mathrm{NH}_{4} \\
+\end{array}$ & 0.16 & 0 & 0.05 & 0.12 & $\begin{array}{c}0.1 \\
3\end{array}$ & 0 & 0 & 0 & 0 & 0 & $\begin{array}{c}0.0 \\
4\end{array}$ & $\begin{array}{c}0.0 \\
3\end{array}$ & $\begin{array}{c}0.2 \\
2\end{array}$ \\
\hline $\mathrm{K}^{+}$ & 2.33 & 1.18 & 1.17 & 1.37 & $\begin{array}{c}1.2 \\
9\end{array}$ & $\begin{array}{c}1.1 \\
7\end{array}$ & $\begin{array}{c}1.2 \\
3\end{array}$ & $\begin{array}{c}1.3 \\
9\end{array}$ & $\begin{array}{c}1.1 \\
4\end{array}$ & $\begin{array}{c}1.3 \\
7\end{array}$ & $\begin{array}{c}2.7 \\
9\end{array}$ & $\begin{array}{c}1.9 \\
6\end{array}$ & $\begin{array}{c}3.4 \\
1\end{array}$ \\
\hline $\mathrm{Na}^{+}$ & 10.2 & 9.05 & 9.65 & 10.3 & $\begin{array}{c}9.1 \\
3\end{array}$ & $\begin{array}{c}9.0 \\
2\end{array}$ & $\begin{array}{c}9.2 \\
9\end{array}$ & $\begin{array}{c}9.9 \\
5\end{array}$ & $\begin{array}{c}9.8 \\
3\end{array}$ & $\begin{array}{c}10 . \\
2\end{array}$ & $\begin{array}{c}9.9 \\
3\end{array}$ & $\begin{array}{c}9.2 \\
2\end{array}$ & $\begin{array}{c}10 . \\
8\end{array}$ \\
\hline $\mathrm{Mg}^{2}$ & 16.7 & 16.8 & 18.03 & 18.5 & $\begin{array}{c}18 . \\
1\end{array}$ & $\begin{array}{c}17 . \\
5\end{array}$ & $\begin{array}{c}17 . \\
7\end{array}$ & $\begin{array}{c}17 . \\
9\end{array}$ & $\begin{array}{c}17 . \\
2\end{array}$ & $\begin{array}{c}17 . \\
4\end{array}$ & $\begin{array}{c}17 . \\
1\end{array}$ & $\begin{array}{c}17 \\
4\end{array}$ & $\begin{array}{c}17 . \\
5\end{array}$ \\
\hline $\mathrm{Sr}^{2+}$ & 0.66 & 0.07 & 0.18 & 0.35 & $\begin{array}{c}0.2 \\
8\end{array}$ & $\begin{array}{c}0.3 \\
9\end{array}$ & $\begin{array}{c}0.3 \\
0\end{array}$ & $\begin{array}{c}0.2 \\
7\end{array}$ & $\begin{array}{c}0.1 \\
9\end{array}$ & $\begin{array}{c}0.3 \\
5\end{array}$ & $\begin{array}{c}0.5 \\
5\end{array}$ & $\begin{array}{c}0.6 \\
2\end{array}$ & $\begin{array}{c}0.4 \\
8\end{array}$ \\
\hline $\mathrm{Ba}^{2+}$ & 0.14 & 0.13 & 0.16 & 0.15 & $\begin{array}{c}0.1 \\
6\end{array}$ & $\begin{array}{c}0.1 \\
7\end{array}$ & $\begin{array}{c}0.1 \\
6\end{array}$ & $\begin{array}{c}0.1 \\
5\end{array}$ & $\begin{array}{c}0.1 \\
5\end{array}$ & $\begin{array}{c}0.1 \\
6\end{array}$ & $\begin{array}{c}0.1 \\
4\end{array}$ & $\begin{array}{c}0.1 \\
3\end{array}$ & $\begin{array}{c}0.1 \\
8\end{array}$ \\
\hline $\mathrm{Ca}^{2+}$ & 57.6 & 53.6 & 59.23 & 61.9 & $\begin{array}{c}61 . \\
7\end{array}$ & $\begin{array}{c}54 . \\
1\end{array}$ & $\begin{array}{c}55 . \\
5\end{array}$ & $\begin{array}{c}59 . \\
4\end{array}$ & $\begin{array}{c}43 . \\
6\end{array}$ & $\begin{array}{c}51 . \\
3\end{array}$ & $\begin{array}{c}47 . \\
9\end{array}$ & $\begin{array}{c}36 . \\
9\end{array}$ & $\begin{array}{c}45 . \\
7\end{array}$ \\
\hline
\end{tabular}

The results analysis revealed that on the 11th day the water samples of infused with shungite showed significant decrease in calcium ions concentration (by $36.0 \%$ ), while in the control the same indicator decreased by $16.8 \%$. It should be added that statistically significant difference in $\mathrm{Ca}^{2+}$ concentrations between the control at the very beginning of the experiment and in the experimental samples occurred on day 7 and 11 respectively. The shungite impact on $\mathrm{Ca}^{2+}$ cations dissolved in water is explained by the fact that the $\mathrm{Ca}^{2+}$ ions are converted by catalytically active shungite into insoluble carbonates, due to the interaction with $\mathrm{CO}_{2}$, which is generated during the organic substances oxidation of with oxygen.

As for the dynamics of other cations concentrations in the water infused with shungite, no significant changes were detected.

On day 11, the water samples infused with flint also showed significant decrease in calcium ions concentration (by 20.5\%), but not much prevailing the control (16.8\%) and no statistically significant difference occurred $(p=0.172128)$. considerable increase is worth mentioning in $\mathrm{K}^{+}$ions concentration in the water samples infused with flint (by $46.3 \%$ compared to the initial concentration), as well as slight increase in $\mathrm{Mg}^{2+}$ ions concentration - by $4.1 \%$ and $4.8 \%$ for water samples infused with shungite and flint, respectively.

The results analysis of Table 3 shows that on Day $11, \mathrm{Cl}^{-}, \mathrm{SO}_{4}{ }^{2-}, \mathrm{NO}_{3}{ }^{-}$-ions concentrations increased slightly in the water samples infused with shungite and flint. The concentration of $\mathrm{CO}_{3}{ }^{2-}$ carbonate ions in the water infused with shungite decreased considerably $(\mathrm{p}=0.014965)$ in the experiment $(28.3 \%$ vs. $11.2 \%$ in the control $)$, and in the water on flint it did not practically change in comparison to the control. It is necessary to note $\mathrm{F}^{-}$ions concentration decrease in the case of water infused with both shungite and flint, but in the water with flint, the concentration decreased by $33.4 \%$, compared to the of the experiment start, and in the water with shungite by $16.7 \%$.

Table 3. Anions amount in water samples infused in control, with shungite and flint ( $\mathrm{mg} / \mathrm{l})$

\begin{tabular}{|c|c|c|c|c|c|}
\hline & $\begin{array}{c}0 \\
\text { day }\end{array}$ & 1 day & 4 day & 7 day & 11 day \\
\hline
\end{tabular}




\begin{tabular}{|l|c|c|c|c|c|c|c|c|c|c|c|c|c|}
\hline & & C & Sh & F & C & Sh & F & C & Sh & F & C & Sh & F \\
\hline $\mathrm{Cl}^{-}$ & 12.7 & 12.7 & 13.3 & $\begin{array}{l}14 . \\
3\end{array}$ & $\begin{array}{l}13 . \\
9\end{array}$ & $\begin{array}{l}13 . \\
3\end{array}$ & $\begin{array}{l}13 . \\
0\end{array}$ & $\begin{array}{l}13 . \\
8\end{array}$ & $\begin{array}{l}13 . \\
2\end{array}$ & $\begin{array}{l}13 . \\
0\end{array}$ & 14.35 & 13.12 & 14.1 \\
\hline $\mathrm{SO}_{4}{ }^{2-}$ & 15.0 & 16.1 & 17.0 & $\begin{array}{l}16 . \\
7\end{array}$ & $\begin{array}{l}17 . \\
7\end{array}$ & $\begin{array}{l}18 . \\
1\end{array}$ & $\begin{array}{l}17 . \\
5\end{array}$ & $\begin{array}{l}18, \\
1\end{array}$ & $\begin{array}{l}18 . \\
8\end{array}$ & $\begin{array}{l}14 . \\
9\end{array}$ & 18.97 & 19.24 & 17.16 \\
\hline $\mathrm{NO}_{3}^{-}$ & 0.58 & 0.59 & 0.61 & $\begin{array}{l}0.6 \\
5\end{array}$ & $\begin{array}{l}0.6 \\
1\end{array}$ & $\begin{array}{l}0.7 \\
0\end{array}$ & $\begin{array}{l}0.7 \\
3\end{array}$ & $\begin{array}{l}0.6 \\
4\end{array}$ & $\begin{array}{l}0.7 \\
1\end{array}$ & $\begin{array}{l}0.6 \\
8\end{array}$ & 0.64 & 0.72 & 0.70 \\
\hline $\mathrm{F}^{-}$ & 0.24 & 0.25 & 0.13 & $\begin{array}{l}0.2 \\
5\end{array}$ & $\begin{array}{l}0.2 \\
1\end{array}$ & $\begin{array}{l}0.2 \\
2\end{array}$ & $\begin{array}{l}0.2 \\
0\end{array}$ & $\begin{array}{l}0.2 \\
2\end{array}$ & $\begin{array}{l}0,1 \\
9\end{array}$ & $\begin{array}{l}0,1 \\
8\end{array}$ & 0.22 & 0.20 & 0.16 \\
\hline $\mathrm{CO}_{3}{ }^{2-}$ & 180 & 166.6 & 165.7 & 179 & 172 & 157 & 156 & 147 & 117 & 139 & 160 & 129 & 162 \\
\hline
\end{tabular}

Thus, analyzing the effect of changing concentrations of cations and anions in water, infused with shungite and flint, we can talk about the effective sorption influence of these natural minerals in relation to $\mathrm{Ca}^{2+}, \mathrm{CO}_{3}{ }^{2-}, \mathrm{F}^{-}$ions. In general it is very important for the Municipal water supply of some areas of the Vladimir region, where increased water hardness is caused by calcium salts and, excessive amounts of fluoride ions, which is associated with the drinking water quality from artesian wells.

\section{Conclusion}

The experiments results detected that when crushed shungite and flint are added to the tap water, alkalinization process is statistically reliable. Simultaneously the total water mineralization decreases due to the shungite and flint sorption regarding $\mathrm{Ca}_{2}^{+}$and $\mathrm{CO}_{3}{ }^{2-}$ ions. When water is infused with flint, it is enriched with $\mathrm{K}^{+}$and $\mathrm{Mg}^{2+}$ ions, which can be very useful for the human body. These natural minerals can be used to purify centralized water from increased hardness and the increased fluoride ions amount, which is necessary for some areas of the Vladimir region, while the local environmentally safe mineral flint of Dobryatinsky deposit can be used as a sorbent.

\section{References}

1. T. A. Trifonova, S. I. Roschina, L. A. Shirkin, O. G Selivanov, M. E. Ilina, Biosciences Biotechnology Research Asia, 12, 2481-2488 (2015) http://dx.doi.org/10.13005/bbra/1927

2. P. Tang, B. Liu, Y. Zhang, H. Chang P. Zhou, M. Feng, V. K. Sharma, Chemical Engineering Journal, 392, 123743 (2020) https://doi.org/10.1016/j.cej.2019.123743

3. S. F. Anis, R. Hashaikeh, N. Hilal, Desalination, 452, 159-195 (2019) https://doi.org/10.1016/j.desal.2018.11.006

4. K. Konieczny, Desalination, 119, 251-258 (1998)

5. M. A. Shahmirzadi, S. S. Hosseini, J. Luo, I. Ortiz, Journal of Environmental Management, 215, 324- 344 (2018)

6. F. Hashemi, H. Hashemi, M. Shahbazi, M. Dehghani, M. Hoseini, A. Shafeie, Water Resources and Industry, 23, 100123 (2020)

7. T. A. Trifonova, A.A. Martsev, O. G. Selivanov, A. A. Podolets, Gigiena i sanitariya, 98, 701-706 (2019) DOI: 10.18821/0016-9900-2019-98-7-701-706

8. Anton Martsev, Oleg Selivanov, E3S Web of Conferences, 164, 01016 (2020) doi.org/10.1051/e3sconf /2020164010 16 
9. O. G. Selivanov, E. S. Pikalov, A. S. Kolosova, International Journal of Emerging Trends in Engineering Research, 8, 1732-1735, (2020) https://doi.org/10.30534/ijeter/2020/39852020

10. A. A. Martsev, A. A. Podolets, Advances in current natural sciences, 11, 62-64 (2015)

11. A. A. Podolets, A. A. Martsev, Advances in current natural sciences, 11, 81-83 (2015)

12. A. P. Ponomariov, L. V. Frolova, Dezinfekciya. Antiseptika, 4, 50 - 58, (2013)

13. I. Ignatov, O. V. Mosin, International Journal of Advanced Scientific and Technical Research, 6, 9-21 (2013)

14. O. G. Selivanov, E. S. Pikalov, A. S. Kolosova, International Journal of Emerging Trends in Engineering Research, 8, $2446-2449$ (2020) https://doi.org/10.30534/ijeter/2020/39862020

15. O. G. Selivanov, E. S. Pikalov, A. S. Kolosova, A. A. Skop, International Journal of Emerging Trends in Engineering Research, 8, 6219 - 6321 (2020) https://doi.org/10.30534/ijeter/2020/226892020 